\title{
INVENTAR EL FUTURO
}

\author{
Inventing the Future \\ Álvaro Ramos Colás \\ Universidad Nacional de Educación a Distancia \\ boskerbosker@yahoo.es
}

Reseña de: SRNICEK, N., WILLIAMS, A. (2016). Inventar el futuro. Poscapitalismo y un mundo sin trabajo. Barcelona: Malpaso. 336 págs.

El poscapitalismo es un tema candente, cosa lógica teniendo en cuenta que vivimos en una época que reposa sobre los rescoldos de una de las peores crisis de los últimos cien años. Marx, completando a Hegel, afirmó en El dieciocho brumario de Luis Bonaparte que los grandes hechos de la historia ocurren dos veces, la primera como tragedia y la segunda como farsa. Interpretada a la luz de este juicio, no cabe duda de que la crisis financiera del 2008 es una farsa cuya tragedia precedente quizá habría que buscar en alguna de las grandes crisis del siglo XX (la de 1929, la del 72-79...). Pero realmente importa poco su origen, lo realmente relevante es el hecho de que la farsa, por mucho que nos haya dañado (y lo siga haciendo) tanto económica como socialmente, tiene todos los visos de volver a hacerlo si no se toman las medidas adecuadas.

Streeck $(2016,2017)$ opina que, de todos modos, ya hemos llegado a un nivel en el que el capitalismo no tiene solución, nos encontramos en un interregno poscapitalista, una suerte de tierra de nadie donde las élites económicas se han hecho ya con el control de la sociedad y más pronto que tarde camparán a sus anchas liquidando totalmente las ya escuálidas democracias. También, aunque por motivos bien distintos, P. Mason (2016) y Rifkin (2016) opinan que el capitalismo está al borde del colapso. La lista no acaba aquí, desde luego, pero lo que nos interesa señalar es que Srnicek y Williams se sitúan dentro del grupo de analistas que no están tan seguros de estemos presenciando su final. Es más, defienden una lucha total y sin ambages para que pase a mejor vida. Inventar el futuro. Poscapitalismo y un mundo sin trabajo, trata precisamente de eso. En primer lugar, es un análisis del presente, en segundo, una propuesta económica alternativa al capitalismo y, en tercero, un programa organizacional de la izquierda.

En cualquier caso, hay que subrayar que el libro reseñado es fundamentalmente político; de hecho, podría entenderse como un desarrollo del Manifiesto aceleracionista publicado un año antes por los autores (en Mackay, Avanessian, 2014). Precisamente por ser un texto eminentemente político y reivindicativo, comienzan los autores con una crítica a la "política folk", que es como ellos denominan el modo 
actual de hacer política. Se caracteriza por ser reactiva (de respuesta a las acciones iniciadas por las corporaciones y gobiernos), actuar a corto plazo y sin plan determinado (tacticismo), privilegia lo local a lo global, lo simple a lo complejo, y lo particular a lo universal (pp. 19-20). La falta de atención a la relación entre los problemas globales y las soluciones locales, tal como anticipó Ulrich Beck (2015), es el gran problema de la sociedad posindustrial y, en especial, puntualizan Srnicek y Williams, de la acción política.

El problema es mucho mayor en el caso de la izquierda, ya que debería aspirar a un cambio global radical. Los autores centran sus críticas en el horizontalismo ${ }^{1}$ popularizado por movimientos como el 15-M, Occupy, consumo ético, el Comité Invisible y tantos otros. El problema de estos planteamientos no reside tanto en que estén equivocados en su punto de partida, sino en que se ensimismen en él (p. 21). Es más, según Srnicek y Williams, es necesario partir de un enfoque como, por ejemplo, el de Occupy, pero debemos trascenderlo, aspirar a globalizarlo, y para ello es necesario un análisis integral del capitalismo sin no recluirse en pequeñas comunidades que teóricamente están al margen del sistema capitalista neoliberal. La izquierda horizontalista se caracteriza por el rechazo a toda forma de dominación, por una defensa sin ambages de la democracia directa y/o de la toma de decisiones mediante el consenso, y por el énfasis en la acción directa. Esto circunscribe a los movimientos de la izquierda folk a lo local y limita su campo de acción. Según los autores, una izquierda con semejantes presupuestos no puede aspirar a revertir el orden neoliberal mundial (p. 56). Si el neoliberalismo tiene una naturaleza expansiva, la fuerza que debe enfrentarse a él también debe serlo o estará condenada a la intranscendencia, como así ha ocurrido, según los autores, con los movimientos horizontalistas.

En esto consiste recuperar modernidad para los autores, en recuperar el futuro. El localismo ha empujado a la izquierda folk a un paradójico antimodernismo. Dado su interés en crear comunidades autónomas al margen de todo, no pueden prefigurar una visión universal y de futuro, que a la postre es lo que define al proyecto de la modernidad (p. 102). Lo más irónico del asunto es que las fuerzas conservadoras son las que enarbolan hoy en día el estandarte de la modernidad y el progreso. El pensamiento único hegemónico sólo está interesado en debatir qué modelo de liberalización asumir, lo cual impide cualquier visión alternativa de futuroEstos son los conceptos clave del libro, el futuro y cómo prefigurar el poscapitalismo, del que el neoliberalismo se ha apropiado arteramente.

Hace ya unos años, C. Crouch (2011) formuló una simple (a la par que inquietante) pregunta: ¿por qué después de la hecatombe de la crisis del 2008 sigue sobreviviendo el neoliberalismo? La respuesta, muy resumida, era que el neoliberalismo es contrafáctico, y que su análisis, en consecuencia, rehuía la confrontación con la realidad. Si no funcionaban sus políticas, era porque no se había profundizado suficientemente en el capitalismo, es decir, que todavía había que profundizar más en las políticas de liberalización. Con este argumento, es fácil de entender que el futuro que marca la

\footnotetext{
${ }^{1}$ La visión opuesta, puede encontrarse, por ejemplo, en Graeber, D. (2013). The Democracy Project. A History, A Crisis, A Movement. New York: Spiegel \& Grau.
} 
ideología neoliberal es unidireccional y, si se aspira a otro alternativo, es necesario un análisis del capitalismo actual distinto del que propone el pensamiento único.

A eso dedican Srnicek y Williams el capítulo 5 del libro, que comienza con una denuncia de los nuevos modos de explotación que la "modernidad" ha traído consigo. Para ello, retomando las tesis de Marx acerca del ejército de reserva, examinan los excedentes de población que se están formando hoy y que, según sus previsiones, formarán un inmenso ejército de "pauper digitales" del futuro (p. 125), que estará formado por la gente que quede arrumbada en los márgenes del sistema, teniendo en cuenta que entre el 47 y el 80 por ciento de los empleos actuales podrían ser automatizables en las próximas dos décadas (p. 127). Esta pérdida de empleos, unido a un crecimiento endémicamente bajo, provocará una mayor precariedad de los que todavía conservan su empleo, una marginalidad sin precedentes de los que lo perdieron, y una guetización de los que ni tan si quiera aspiran a trabajar (p. 152).

Ante este sombrío horizonte, menos lejano de lo que parece, los autores intentan reformular el futuro con una agenda basada en tres demandas. La primera es la automatización plena, es decir, el uso de todas las tecnologías disponibles para el aumento de la producción y de la riqueza. Según Srnicek y Williams, el sistema actual no aprovecha toda la tecnología disponible para crear riqueza, sino sólo selectivamente como un medio para afianzar posiciones de mercado y, por tanto, los beneficios empresariales. Con el desarrollo y aplicación de todas las nuevas tecnologías productivas (las máquinas, robots, algoritmos de recolección de datos, etc.) se encargarían de liberar a la humanidad de los esfuerzos necesarios para realizar estos bienes y servicios, posibilitando así el desarrollo de las capacidades individuales de los ciudadanos. Esta tesis (p. 157 ss.), que toma pie en el famoso fragmento de Marx sobre las máquinas en los Grundrisse, los lleva a defender con entusiasmo la robotización, las nuevas tendencias para la recolección de datos (radiofrecuencias, macrodatos), servicios al cliente completamente informatizados y el comercio electrónico basados por completo en algoritmos, y, como no, todo lo referente a la distribución y logística (drones, vehículos autónomos, almacenes automatizados, etc.). Según los autores, se pasaría de una economía de la escasez a otra de la abundancia, con lo que los mercados, tal y como los conocemos hoy, dejarían de tener sentido. ${ }^{2}$

La segunda repropone una vieja demanda de la izquierda clásica, a saber, la reducción de la jornada laboral manteniendo el salario (p. 165). No cabe duda de que, si se consigue la primera, caerá por su propio peso la reducción de las horas de trabajo, pero por lo que hay que luchar políticamente es por el mantenimiento de los salarios, para evitar que el consiguiente aumento de la productividad acabe materializado en beneficios empresariales. Las ventajas de la reducción de la jornada laboral son varias. Obviamente, un aumento del tiempo libre, pero hay otras como las mejoras medioambientales (menos consumo de recursos), mejoras en la salud física y psíquica de los ciudadanos, el asociacionismo de los trabajadores se vería facilitado al disfrutar de más tiempo libre, etc.

\footnotetext{
${ }^{2}$ Recordemos que para que el mercado pueda asignar precios, es necesaria la escasez. Este es un dogma del capitalismo para muchos autores, incluido los del presente volumen.
} 
La tercera demanda reclama la instauración de un ingreso básico universal (IBU), que según los autores debe ser universal e igual para todos. Las consecuencias materiales del IBU como la reducción de la pobreza y de la marginalidad no se harían esperar. Además, Srnicek y Williams indican otras no tan evidentes, como la posibilidad de generar una simetría de poder entre capital y mano de obra, dado que el trabajador no se vería obligado a malvenderse en el mercado de trabajo (p. 182). Como se puede apreciar, estas propuestas están entrelazadas entre sí, y presentan, o lo intentan, una prefiguración alternativa del futuro.

Pero estas tres demandas realmente son sólo una posibilidad entre otras muchas. Lo realmente complicado es poder ponerlas en práctica, conseguir revertir la situación política de tal modo que el "sentido común" neoliberal acabe dando paso a un modo de pensar alternativo que abone el terreno para un cambio social radical. De lo que se trata, a fin de cuentas, si seguimos la terminología gramsciana, es de construir un proyecto contrahegemónico que consiga trascender los logros a corto plazo en los que se ha centrado el horizontalismo folk (p. 193).

La construcción de este contrapoder requiere, en primer lugar, un movimiento populista de masas. La consideración del proletariado como sujeto revolucionario ha fracasado, por eso proponen, siguiendo a Laclau, la convergencia de fuerzas e identidades transformadoras frente a un enemigo común. El concepto aglutinador, además del enemigo común, es la política antitrabajo anteriormente citada. Sin aportar demasiados argumentos ni datos, los autores opinan que el programa del postrabajo aglutinará a los activistas feministas, poscoloniales, indigenistas, obreristas, etc. (p. 231). También consideran que es necesario superar el fetichismo organizativo del horizontalismo localista. Srnicek y Williams critican, en definitiva, que la idea de la participación política en estas corrientes actuales de la izquierda es meramente procedimental, o lo que es lo mismo, privilegian el cómo (asambleas, derecho a veto, acciones directas, etc.) frente al contenido, que para los autores es la sociedad postrabajo.

Inventar el futuro, desde nuestro punto de vista, es interesante como desarrollo (político) del manifiesto aceleracionista, una suerte de Ilamamiento a la acción y al análisis, aunque esto último, en ciertas ocasiones, se echa un poco en falta en el libro. En cualquier caso, es de agradecer el soplo de aire fresco y crítico que aporta al panorama de la izquierda actual, donde la autocrítica, en general, brilla por su ausencia. Se trata de un interesante punto de partida, de una voz que clama por un futuro (poscapitalista) alternativo, así como un conjunto de propuestas para que la tragedia no se nos siga presentando como farsa ad infinitum.

\section{REFERENCIAS}

BECK, U. (2015). La sociedad del riesgo. Hacia una nueva modernidad. Barcelona: Paidós. [1986].

CROUCH, C. (2011). The Strange Non-Death of Neoliberalism. Cambridge: Polity Press.

GRAEBER, D. (2013). The Democracy Project. A History, A Crisis, A Movement. New York: Spiegel \& Grau. 
LACLAU, E., (2005). La razón populista. México D.F.: F.C.E.

MACKAY, R., AVANESSIAN, A., (2014). \#Accelerate. The Accelerationist Reader. Falmouth: Urbanomic Media.

MARX, K. (1972) Elementos fundamentales para la crítica de la economía política (Grundrisse) 1857-1858, 2 volúmenes, México: Siglo XXI.

MASON, P. (2016). Postcapitalismo. Hacia un nuevo futuro. Barcelona: Paidós.

STREECK, W. (2017). Buying Time. The Delayed Crisis of Democratic Capitalism. London/ New York: Verso. Edición en castellano (2016). Comprando tiempo. Madrid: Katz.

- (2016a). How Will Capitalism End?. London/New York: Verso. Edición en castellano (2017). ¿Cómo terminará el capitalismo?. Madrid: Traficantes de Sueños. 